\title{
IS THERE SEASONALITY IN THE MONTH OF BIRTH OF PATIENTS WITH AUTOIMMUNE THYROID DISEASES?
}

\author{
AM Ramos-Leví, A Serrano-Somavilla, R Martínez-Hernández, M Sampedro-Núñez, \\ A Vicuña, M Zelada, M Marazuela.
}

Department of Endocrinology and Nutrition. Instituto de Investigación Sanitaria Hospital Universitario La Princesa (IIS-HUP). Hospital Universitario La Princesa, Universidad Autónoma de Madrid, SPAIN

\section{BACKGROUND}

Graves' disease (GD) and Hashimoto's thyroiditis (HT) are common disorders with an autoimmune etiology, which are known as autoimmune thyroid diseases (AITD). A specific seasonal pattern of the month of birth has been suggested in several autoimmune disorders, supporting the hypothesis of a link between viral infections and the development of aberrant immune-regulatory mechanisms. However, there are few studies which specifically address this issue in AITD.

\section{MATERIALS AND METHODS}

We reviewed the month of birth of a large cohort of patients with AITD at a single tertiary-care reference hospital. We compared this cohort with the total number of newborns in our city between 1996 and 2011. Chisquare and Hewitt tests were used to analyze seasonality.

\section{RESULTS}

We included a total of 417 patients ( $270 \mathrm{GD}$ and $147 \mathrm{HT}$ ) (figure 1 ), with a mean age of $49.1 \pm 14.3$ years old. The majority of our patients were women $(357,85.6 \%)$ (figure 2).

January, May and November were the months in which the majority of patients were born (figure 3 ). The winter/summer ratio was 0.98 . Hewitt test was not statistically significant (for $k=3, T=24, p=0.992$; for $k=6$, $T=40, p>0.880)$

Taking the number of births in each month in Madrid as reference values, there were no significant differences between the number of births observed in patients with AITD and the number of births expected throughout the whole cohort.

Tampoco se observaron diferencias en el porcentaje de nacimientos mensuales entre sexos ni entre el grupo de EG y de TH. There were no differences in the percentage of births in each month between sexes or between the types of AITD (GD vs TH).

Seasonality was neither observed for the month of diagnosis in patients with $G D$ (for $k=3, T=24, p=0.992$ ). ) (figure 4).
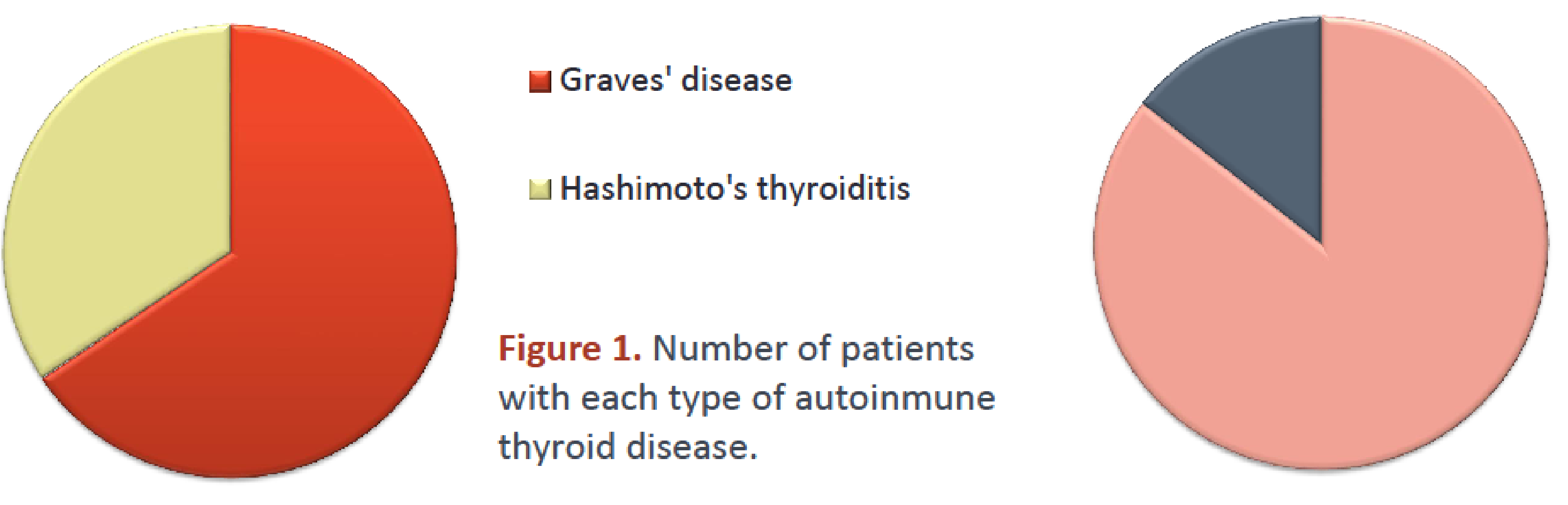

GWomen $\quad$ Men

Figure 2. Distribution of sex in patients with thyroid autoinmune disease.

Figure 3. Number of births in each month of the year

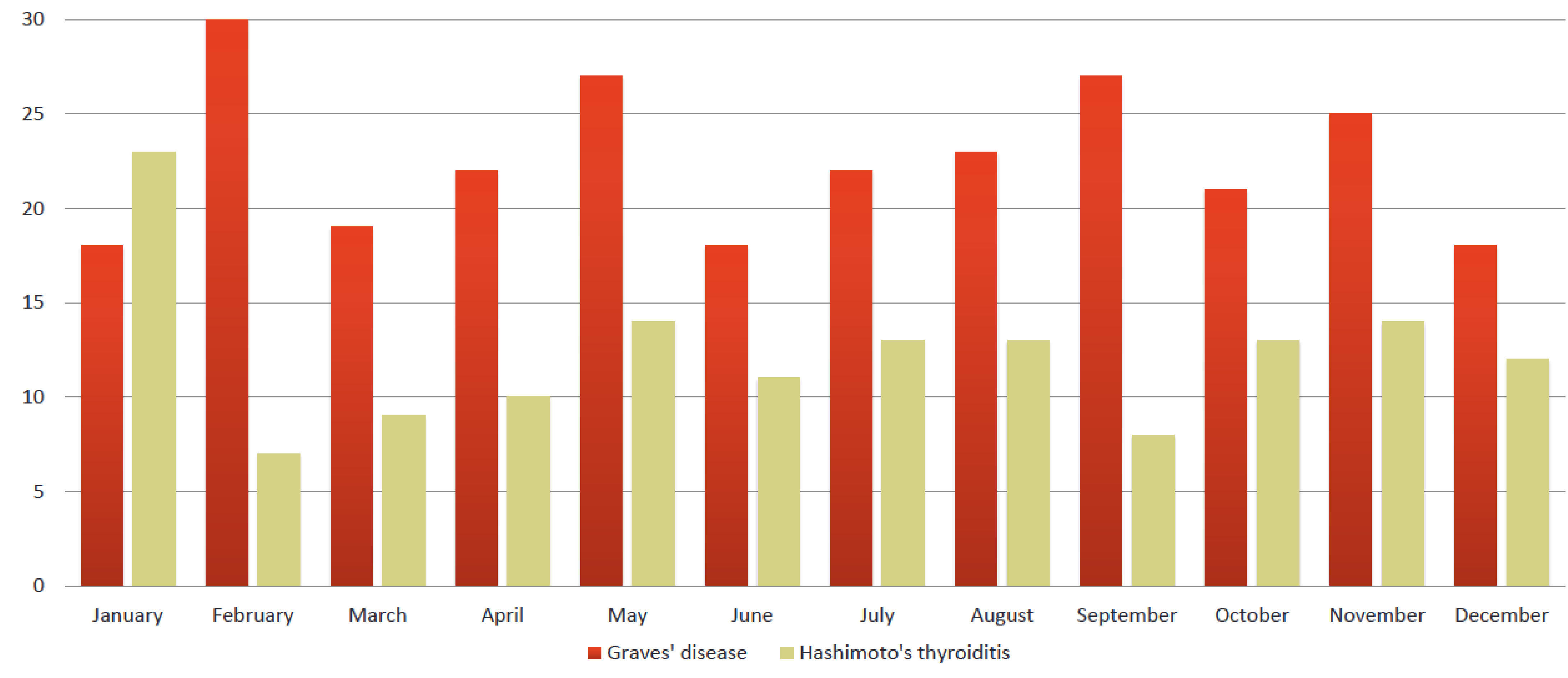

Figure 4. Month of diagnosis of Graves' disease

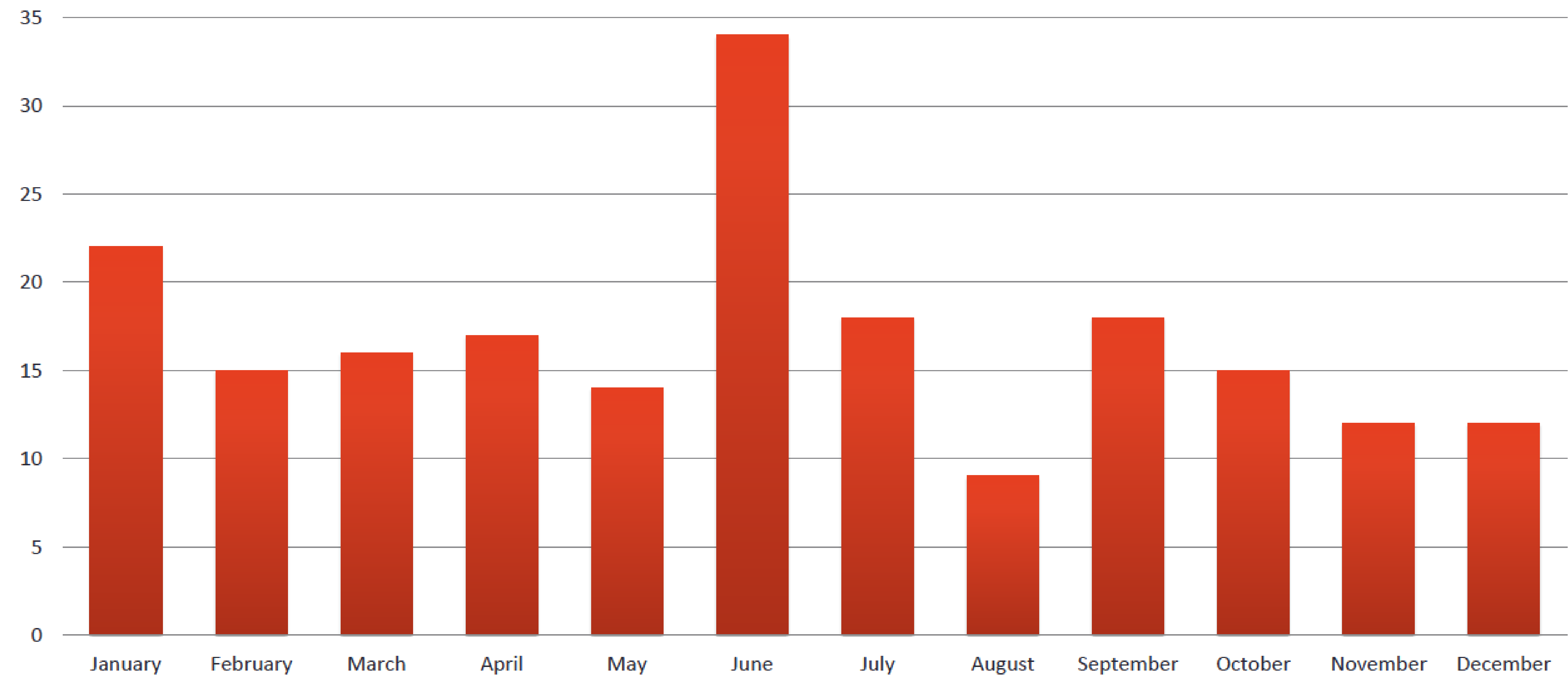

\section{CONCLUSIONS}

Our results suggest that there is no specific seasonal pattern in the month of birth in patients with AITD. This could favor the hypothesis of further mechanisms involved in the development of autoimmunity, different from those observed in other autoimmune diseases in which a seasonality was observed.

ACKNOWLEDGEMENTS: Grants from Fundación SEEN Award for Young Endocrinologists, FIS 13/1414 and PIE 13/41. 